\title{
Immediate assessment of fine needle aspiration cytology of lung
}

\author{
C J R Stewart, I S Stewart
}

\begin{abstract}
Aims-To assess the value of immediate assessment of cytology in percutaneous fine needle aspiration (FNA) cytology of lung.

Methods-FNA specimens from 75 consecutive patients with suspected pulmonary neoplasms were subjected to immediate cytology assessment. Direct smears were prepared in the radiology department and stained using the Diff Quik method. The cellular content was assessed and, if possible, a provisional diagnosis offered. A second FNA was requested if the initial aspirate seemed of doubtful adequacy. The diagnostic accuracy was examined by review of clinical and radiological data in all patients, and by correlation with other histological or cytological material in 25 patients. Complications of the procedure were identified during the clinical review.
\end{abstract}

Results-Two of 75 specimens were inadequate for diagnosis. Satisfactory diagnostic material was obtained in 51 patients on a single aspirate and following a second FNA in 22 patients. Of the 73 satisfactory aspirates, 58 were malignant, one highly suspicious of malignancy and 14 reported as negative for malignancy. All malignant diagnoses were confirmed on clinical or pathological review. FNA accurately distinguished primary small cell and large cell carcinomas in those patients with pathological follow up. There were two false negative reports, one due to sampling error and the other due to misinterpretation of aspirate material. The diagnostic specificity was $100 \%$ and sensitivity $\mathbf{9 6 . 6 \%}$. Complications were recorded in seven $(9.3 \%)$ patients, five of whom developed pneumothorax; a chest drain was required in one patient.

Conclusions-Percutaneous FNA cytology provides safe and accurate diagnosis in the investigation of pulmonary lesions. Immediate cytology assessment ensures that aspirate material is handled optimally, and those patients requiring further sampling or ancillary investigation identified rapidly. The number of unsatisfactory and false negative lung FNA are therefore reduced. The complication rate is minimised by decreasing the number of pleural punctures.

( Clin Pathol 1996;49:839-843)

Keywords: fine needle aspiration, cytology, immediate assessment.
Fine needle aspiration (FNA) cytology offers safe, rapid and accurate diagnosis in patients with pulmonary mass lesions. ${ }^{1-4}$ Numerous reports have shown that aspiration cytology is highly reliable, particularly in the diagnosis of lung carcinoma. A review of thoracic FNA by Sterrett et al ${ }^{5}$ revealed a specificity of $100 \%$ for a malignant diagnosis in many studies. A recent multicentre analysis by the College of American Pathologists, in which lung FNA was correlated with histology, also showed an overall positive predictive value of $99 \% .{ }^{6}$ However, a negative result is generally less reliable and most reports document a false negative rate of $10-20 \%$ for lung aspiration cytology. The major contributing factor to the lower sensitivity of the technique has been failure to obtain diagnostic material. ${ }^{7}$ In addition, a variable number of aspirates are considered inadequate or unsatisfactory for evaluation.

Some studies have suggested that immediate cytology assessment of FNA specimens is of value in minimising the number of false negative and unsatisfactory specimens..$^{8-12}$ Smears from the aspirate are stained rapidly and examined in the radiology department by a cytopathologist, permitting assessment of cell yield and content. Repeat FNA can be advised if the initial aspirate seems inadequate or unrepresentative. This approach seems to be advantageous in that diagnostic material is handled optimally and immediate clinical and radiological correlation is possible, but it has not been advocated by all authors. ${ }^{13}{ }^{14} \mathrm{We}$ introduced a rapid cytology assessment protocol with lung FNA in 1994 and herein report 75 consecutive aspirates with immediate cytology assessment performed in our hospital between January 1994 and December 1995.

\section{Methods}

Consecutive lung FNA $(n=75)$ with immediate cytology assessment performed in Glasgow Royal Infirmary between January 1994 and December 1995 were studied. All patients had one or more discrete lung masses on radiological examination and the major clinical suspicion in all patients was of neoplastic disease.

The aspirates were performed using $21 \mathrm{G}$ needles attached to $20 \mathrm{ml}$ syringes with fluoroscopic control for needle guidance in most cases; computed tomography and ultrasound were used occasionally. Following needle placement the aspirate was obtained by agitating the needle tip within the lesion, and four to eight direct smears were made immediately from the sample in the scanning room. The needle was rinsed thereafter in sterile normal saline. Two or more direct smears were stained 
Table 1 Correlation of lung FNA with final clinical diagnosis

\begin{tabular}{lll}
\hline Lung FNA & \multicolumn{2}{l}{ Clinicopathological diagnosis } \\
\cline { 2 - 3 } & Malignant & Benign \\
\hline Maligant $(\mathrm{n}=58)$ & 58 & 0 \\
Suspicious $(\mathrm{n}=1)$ & 1 & 0 \\
Benign $(\mathrm{n}=14)$ & 2 & 12 \\
\hline
\end{tabular}

by the Diff Quik method for rapid assessment and the remaining slides dried in air and fixed in alcohol for routine May-Grünwald-Giemsa and Papanicolaou staining, respectively. If the first aspirate was considered of doubtful adequacy a second FNA was requested. No patient had more than two aspirates taken.

The needle rinses were not processed routinely. However, histochemical stains were performed on cytospin preparations in 21 patients, most commonly for demonstration of mucins in poorly differentiated large cell carcinomas. Immunocytochemistry was performed in five FNA, to confirm the epithelial nature of the tumour in three patients, to demonstrate endocrine differentiation in an atypical carcinoid tumour, and to confirm the mesenchymal nature of a benign spindle cell tumour. The needle rinse sample was submitted for microbiology in patients showing an inflammatory or reactive pattern on rapid assessment.

The major indication for immediate cytology assessment was to assess the adequacy of the specimen. However, a provisional diagnosis was also made whenever possible based on the rapidly stained smears.

\section{CLINICAL AND PATHOLOGICAL CORRELATION}

The accuracy of the lung FNA diagnoses was assessed in all patients by clinical follow up and by histological/cytological correlation with further specimens when these were available.

Hospital case records were reviewed in 69 patients and clinical information provided by referring physicians or general practitioners in six. A malignant diagnosis was confirmed by the patients' clinical course, the documentation of metastases and/or by progression of the radiological lesion.

A histological diagnosis was obtained subsequently in 19 patients, 15 of which were malignant and four benign. These included 10 lobectomy or pneumonectomy specimens, one necropsy and eight biopsy specimens. One

Table 2 Correlation with tumour subtyping in 20/55 primary lung carcinomas

\begin{tabular}{lllll}
\hline $\begin{array}{l}\text { FNA (number } \\
\text { correlated/total) }\end{array}$ & Histological/cytological correlation & & \\
\cline { 2 - 5 } & $\begin{array}{l}\text { Small cell } \\
\text { carcinoma }\end{array}$ & $\begin{array}{l}\text { Large cell NOS } \\
\text { carcinoma }\end{array}$ & $\begin{array}{l}\text { Squamous cell } \\
\text { carcinoma }\end{array}$ & Adenocarcinoma \\
\hline $\begin{array}{l}\text { Small cell } \\
\text { carcinoma (4/7) }\end{array}$ & $4^{\star}$ & - & - & - \\
$\begin{array}{c}\text { Large cell NOS } \\
\text { carcinoma } \\
(6 / 25)\end{array}$ & - & 2 & 2 & 2 \\
$\begin{array}{c}\text { Squamous cell } \\
\text { carcinoma } \\
(6 / 11)\end{array}$ & - & - & 6 & - \\
$\begin{array}{c}\text { Adenocarcinoma } \\
(4 / 12)\end{array}$ & - & - & - & 4 \\
\hline
\end{tabular}

^All confirmed on subsequent cytology specimens. patient with multiple lung metastases had a history of biopsy confirmed transitional cell carcinoma of bladder. An independent cytological diagnosis was obtained in an additional $c$ five patients, four of whom had lung FNA $\Omega$ diagnosis of small cell carcinoma and one an $\overline{\bar{F}}$ adenocarcinoma. These included FNA of cervical lymph node metastases in two patients and sputum, pleural fluid and cerebrospinal fluid cytology in one patient each.

Case records were also examined with refer- $\bar{\tau}$ ence to any complications of the FNA procedure.

The diagnostic specificity and sensitivity $\stackrel{\mathbb{\Omega}}{\Omega}$ were calculated by standard methods. ${ }^{15}$

\section{Results}

Two aspirates were considered unsatisfactory. In both patients the pulmonary lesions were centrally located and a small pneumothorax ? noted after the first FNA. Therefore, second $\overrightarrow{0}$ aspirates were not performed.

Seventy three FNA were satisfactory for examination. A single aspirate was adequate in 6 51 patients and a second aspirate requested in 을 22 patients. The results of lung FNA and the $\overrightarrow{-}$ final clinicopathological diagnoses for the 73 O satisfactory patients are summarised in table 1 .

An unequivocal malignant diagnosis was $\stackrel{\Phi}{-}$ made in 58 aspirates, all of which were $\vec{\varphi}$ confirmed on subsequent clinical or pathologi- $\mathscr{\&}$ cal review. Fifty seven patients were thought to have primary lung malignancy and one a metastatic transitional cell carcinoma of bladder. In one further patient the FNA was considered highly suggestive of large cell carcinoma but not completely conclusive as numerous inflam- $\vec{a}$ matory cells were also present. However, the cytology was considered sufficient for clinical management as the patient was not a candidate for radical treatment. This was a peripheral lesion which had shown slow growth over 20 ? months despite local radiotherapy and clinically was considered a low grade carcinoma.

Tumour subtyping in the 58 patients with $\frac{1}{3}$ malignancies was as follows: small cell carcinoma in seven patients; large cell carcinoma, not otherwise specified (NOS) in 25 patients; squamous carcinoma in 11 patients; adenocarcinoma in 12 patients; atypical carcinoid, 0 metastatic transitional cell carcinoma and car- $N$ cinoma NOS in one patient each.

Independent pathological material was avail- 0 able for correlation in 20 of the 55 primaryo malignant tumours (table 2). FNA distinguished accurately the clinically important $\stackrel{\mathcal{S}}{\rightarrow}$ subgroups of small cell carcinoma and large $\frac{T}{0}$ cell carcinoma in all patients. The more $\underset{\mathbb{D}}{\stackrel{\circ}{\mathbb{D}}}$ specific diagnoses of squamous carcinoma or $\frac{\rho}{\Phi}$ adenocarcinoma were also confirmed in the $10 \stackrel{\mathbb{2}}{2}$ patients in which this distinction was possible? on the aspirate. However, four of the six 8 tumours regarded as large cell carcinoma NOS on FNA showed squamous or glandular differentiation in subsequent surgical resection specimens.

Fourteen aspirates were considered satisfactory for evaluation but with no evidence of malignancy. A benign clinical course confirmed the FNA assessment in 12 patients, 


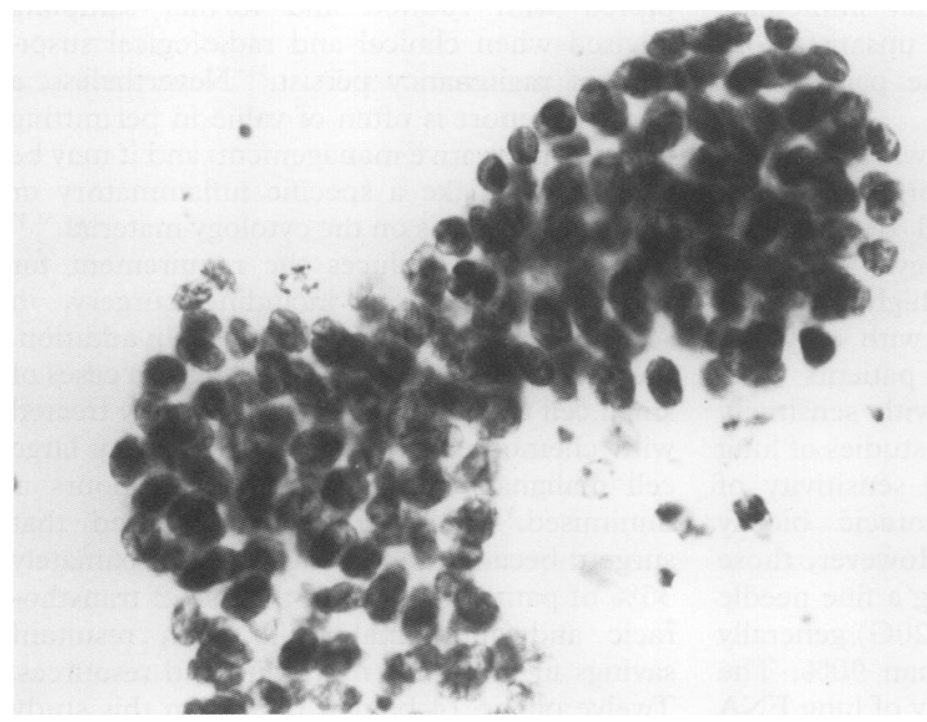

Figure 1 Three dimensional cluster of slightly crowded but cytologically uniform cells from a bronchioalveolar carcinoma.

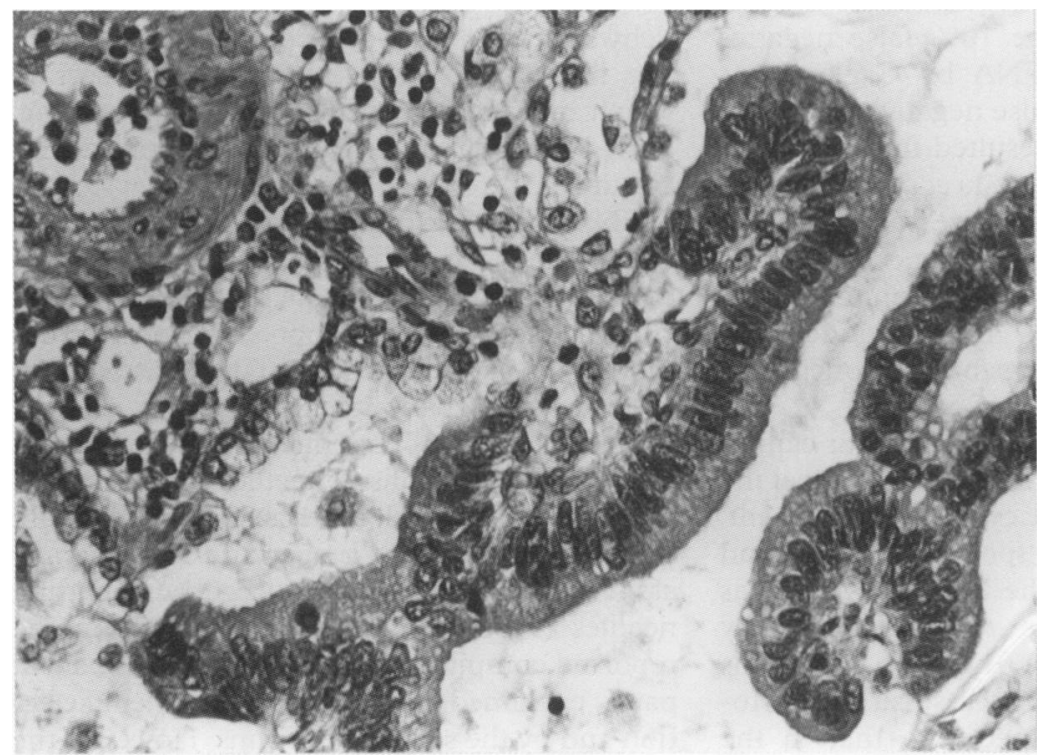

Figure 2 Well differentiated adenocarcinoma showing bronchioalveolar pattern of spread.

most of whom were subsequently thought to have had resolving pneumonic consolidation. Transbronchial lung biopsy was performed in two of these patients and showed an inflammatory process in both. Necropsy confirmed the FNA diagnosis of lung abscess in another patient. A specific benign diagnosis was made in only one FNA, this being a circumscribed peripheral lesion that was reported as a benign mesenchymal tumour and subsequently shown to be Schwannoma on excision biopsy.

There were two false negative FNA reports. The first was a 41 year woman with a history of respiratory insufficiency and patchy left upper lobe consolidation. The aspirate was mainly comprised of reactive epithelium and histiocytes but included a few crowded epithelial groups exhibiting papillary-like architecture. These groups showed orderly nuclear distribution, minimal cytological atypia and a low columnar border in areas (fig 1). No specific diagnosis was made on the aspirate material. Resection showed an adenocarcinoma of variable grade but with well differentiated foci comprised of tall mucin secreting cells exhibiting a bronchioalveolar pattern of spread (fig 2). The second false negative FNA involved a left lower lobe lesion in a 56 year old woman with previously diagnosed squamous carcinoma of right bronchus. The aspirate mainly comprised reactive epithelium and haemosiderin laden histiocytes and the possibility of pulmonary haemorrhage or infarct was raised. The lesion persisted and subsequent lung and lymph node biopsy specimens showed a large B cell lymphoma. Review of the aspirate material showed occasional lymphoid cells but even in retrospect these seemed insufficient to suggest a diagnosis of lymphoma.

Complications were described in seven (9.3\%) patients. One patient complained of severe pain following the procedure which settled with analgesia and another developed haemoptysis. There were five cases of pneumothorax, one of which was also associated with haemoptysis. A temporary chest drain was required in only one patient, who made a full recovery. No other complications were recorded.

\section{Discussion}

The role of immediate cytology assessment in radiologically directed FNA specimens has been the subject of controversy. Although this approach has been documented for many years it is not universally accepted. Disadvantages include the requirement for an experienced cytopathologist in, or close to, the radiology department and the increased time for the biopsy procedure due to staining and examination of smears. ${ }^{13}$ In addition, some reports have not documented improvements in diagnostic accuracy or a lowered complication rate when immediate cytology assessment is performed. ${ }^{13}{ }^{14}$ However, other studies had shown a reduction in the number of inadequate specimens, an increased sensitivity for a malignant diagnosis and/or a decrease in the incidence of pneumothorax with rapid cytology examination of lung FNA specimens. ${ }^{8-1216}$ Gasparini $e t$ al suggested recently that immediate cytology assessment offers both improvements in diagnosis and time and cost savings in the investigation of lung lesions. ${ }^{17}$

It is difficult to identify the unsatisfactory rate of lung FNA in some studies as inadequate aspirates have been excluded from analysis, not specifically documented or combined with negative reports. The importance of separating non-diagnostic from negative but adequate specimens had been emphasised by Zakowski et al. ${ }^{18}$ Crosby et al ${ }^{19}$ found that $16 \%$ of specimens were inadequate for evaluation, while Alonso et $a l^{20}$ reported that $60 / 344$ aspirates were unsatisfactory, reducing the sensitivity of lung FNA in their series from $93 \%$ to $71 \%$ when these patients were taken into account. A large series of thoracic aspirates from the Toronto General Hospital ${ }^{4}$ and a recent multicentre analysis from US laboratories of more than 13000 FNA $^{6}$ recorded unsatisfactory rates of $6 \%$ and $9 \%$, respectively. In this study only two $(2.7 \%)$ of 75 FNA were unsatisfactory, the procedure in both patients being lim- 
ited to a single aspirate because of pneumothorax. Like others ${ }^{8-10}$ we feel that immediate cytology assessment minimises unsatisfactory procedures by identifying those patients requiring further sampling.

The diagnosis of malignancy was confirmed in all our patients by clinical or pathological follow up, illustrating the well documented specificity of lung FNA cytology. ${ }^{7} 1^{21} 22$ Of more interest was the relatively high sensitivity of FNA in our study (96.6\%) with only two false negative reports in 59 patients with malignancies. This compares with sensitivity rates of $78-94 \%$ in other recent studies of lung FNA ${ }^{7}{ }^{17}{ }^{22-25}$ and a range in sensitivity of $75-96 \%$ in a review of thoracic biopsy specimens by Sterrett et al. ${ }^{5}$ However, those studies in the latter review using a fine needle technique (needle smaller than $20 \mathrm{G}$ ) generally reported a sensitivity of less than $90 \%$. The factor which limits the sensitivity of lung FNA is sampling error in most patients, misinterpretation of the cytology material being relatively uncommon. ${ }^{341826} 27$ Inadequate sampling was solely responsible for the $10 \%$ false negative rate reported in lung FNA by Cagle et al. ${ }^{7}$ Similarly, 11 of the 13 false negative reports in the series of Caya et al resulted from unrepresentative aspirates. ${ }^{28}$ Zakowski et al ${ }^{18}$ found that FNA had a negative predictive value of $53 \%$, the largest contributing factor being false negative specimens due to sampling error. False negative aspirates may include only normal or reactive elements but necrotic material is an additional source of error..$^{1527} 29$

While the problem of sampling error cannot be entirely eliminated in lung FNA, we feel the risk is reduced by rapid cytology assessment. As with unsatisfactory specimens, a second aspirate is obtained if the initial FNA seems unrepresentative. Conces et $a l^{10}$ reported only two false negative FNA in 61 benign specimens using an immediate cytology assessment protocol similar, in most respects, to that in the present study. We agree with Weisbrod ${ }^{2}$ that the close radiological correlation offered by immediate cytology assessment is of great value in the interpretation of lung aspiration cytology material, particularly in the context of an apparently 'negative' sample. In addition, should the initial aspirate show only degenerative or necrotic material, the radiologist can be guided to a more peripheral area of the lesion for further sampling. In this study a second FNA was requested in 22 patients, all of which finally included diagnostic material. There was only one false negative report due to sampling error, that of a malignant lymphoma. The aspirate in this patient was cellular but was considered suggestive of pulmonary haemorrhage or infarct. The other false negative report, in a patient with an adenocarcinoma with focal bronchioalveolar pattern, was principally an interpretative error as review showed that tumour cells were present in the smears. Bronchioalveolar carcinoma may present diagnostic difficulties in a variety of cytological specimens but the appearances of these tumours in lung FNA have been described in detail. ${ }^{30} 31$

As occasional false negative results are inevi- table, a benign lung FNA report must be interpreted with caution and further sampling advised when clinical and radiological suspicion of malignancy persist. ${ }^{32}$ Nevertheless, a negative report is often of value in permitting initial conservative management, and it may be possible to make a specific inflammatory or infective diagnosis on the cytology material. ${ }^{33} 34$ FNA therefore reduces the requirement for further investigation, including surgery, in some patients with benign disease. In addition, the need for diagnostic thoracotomy in cases of small cell carcinoma, which are usually treated with chemotherapy, inoperable primary large cell malignancies and metastatic tumours is है minimised. ${ }^{42}$ Tao et al $^{4}$ commented that surgery became unnecessary in approximately $35 \%$ of patients following the use of transthoracic and abdominal FNA, with resultant savings in mortality, morbidity and resources. Twelve of the 14 benign reports in this study proved to be accurate, a negative predictive value of $86 \%$, and only one of these patients subsequently underwent surgery (to remove a Schwannoma). Rapid cytological assessment was also of value in selecting those cases in which microbiology was indicated as material from inflammatory lesions was submitted for culture.

FNA has been shown to be a safe technique. $\vec{\bullet}$ Nevertheless, as with any invasive procedure $\%$ complications may arise. The most common complications are haemoptysis and pneumothorax, the latter occurring in $20-30 \%$ patients in most series although the range is wide. ${ }^{35}$ Only a minority of patients require chest drain insertion. Air embolism, needle tract implantation by tumour and death are extremely rare complications of lung biopsy and are generally associated with the use of large bore cutting needles $(16-20 \mathrm{G}) .^{2}{ }^{5}$ The wide range in the reported complication rate of lung FNA can be partly explained by differences in patient selection and by the site of the lesions. However, the procedure is made safer by use of smaller needles (smaller than 20G) and by limiting the number of punctures. $^{5}{ }^{21}{ }^{34}$ In our study satisfactory material was obtained in the initial FNA in approximately two thirds of patients, minimising the requirement for a further os puncture. None of our patients underwent $\tilde{N}$ more than two punctures. Other authors have $\mathrm{\omega}$ performed two aspirates routinely ${ }^{13}{ }^{23}$ or up to three aspirates depending on visual inspection of the sample. ${ }^{2132} 34$ De Gregoria et al ${ }^{21}$ noted a fall in the rate of pneumothorax from $23 \%$, when three aspirates were performed routinely, 0 to $13 \%$ when a single aspirate was used in most $\overrightarrow{\mathbb{D}}$ patients. We believe that restricting the procedure to a single aspirate in 51/73 diagnostic cases partly explains the low rate of pneumothorax of $6.7 \%$ in this study. Most lung FNA in 8 our hospital are also performed by one experienced radiologist, an additional factor which reduces the risk of the procedure.

In conclusion, we have shown that FNA is a safe, accurate technique providing rapid diagnosis in patients with pulmonary mass lesions. In our view immediate cytology assessment provides optimum material for diagnosis, 
minimises the number of inadequate specimens, ensures maximum specificity and sensitivity, and helps to limit the risk of complications.

1 Salazar AM, Westcott JL. The role of transthoracic needle biopsy for the diagnosis and staging of lung cancer. Clin Chest Med 1993;14:99-110.

2 Weisbrod GL. Transthoracic percutaneous lung biopsy. Radiol Clin North Am 1990;28:647-55.

3 Sanders C. Transthoracic needle aspiration. Clin Chest Med 1992;13:1-16.

4 Tao LC, Sanders DE, Weisbrod GL, Ho CS, Wilson S. Value and limitations of transthoracic and transabdominal fine-needle aspiration cytology in clinical practice. Diagn Cytopathol 1986;2:271-6.

5 Sterrett G, Whitaker D, Glancy J. Fine-needle aspiration of lung, mediastinum, and chest wall. A clinicopathologic exercise. Pathol Annu 1982;17:197-228.

6 Zarbo RJ, Fenoglio-Preiser CM. Interinstitutional database for comparison of performance in lung fine-needle aspirafor comparison of performance in lung fine-needle asp

7 Cagle PT, Kovach M, Ramzy I. Causes of false results in transthoracic fine needle aspirates. Acta Cytol 1993;37:16-20.

8 Pak HY, Yokota S, Teplitz RL, Shaw SL, Werner JL. Rapid screening techniques employed in fine-needle aspirations of the lung. Acta Cytol 1981;25:178-84

9 Silverman JF, Finley JL, O'Brien KF, Dabbs DJ, Park HK, Larkin EW, et al. Diagnostic accuracy and role of immediate interpretation of fine-needle aspiration biopsy speciate interpretation of fine-needle aspiration biopsy

10 Conces DJ, Schwenk GR, Doering PR, Glant MD. Thoracic Conces DJ, Schwenk GR, Doering PR, Glant MD. Thoracic
needle biopsy. Improved results utilizing a team approach. Chest 1987;91:813-16.

11 Austin JH, Cohen MB. Value of having a cytopathologist present during percutaneous fine-needle aspiration biopsy of lung: report of 55 cancer patients and meta-analysis of the literature. $A \mathcal{F} R A m \mathcal{f}$ Roentgenol 1993;160:175-7

12 Sterrett GF, Frost F, Whitaker D. Tumours of lung and mediastinum. In: Gray W, ed. Diagnostic cytopatholgy. Edinburgh: Churchill Livingstone, 1995:69-128.

13 Ward SC, Carey BM, Chalmers AG, Sutton J. The role of immediate cytological evaluation in CT-guided biopsy. Clin Radiol 1994;49:531-4.

14 Padhani AR, Scott W, Cheema M, Erozan YS. The value of immediate cytological evaluation for needle aspiration lung biopsy. Clin Radiol 1995;50:350

15 Veale D, Gilmartin JJ, Sumerling MD, Wadehra V, Gibson GJ. Prospective evaluation of fine needle aspiration in the diagnosis of lung cancer. Thorax 1988;43:540-4

16 Johnsrude IS, Silverman JF, Weaver MD, McConnell RW. Rapid cytology to decrease pneumothorax incidence after percutaneous biopsy. AfR Am f Roentgenol 1985;144:793-4.

7 Gasparini S, Ferretti M, Secchi EB, Baldelli S, Zuccatosta L, Gusella P. Integration of transbronchial and percutane- ous approach in the diagnosis of peripheral pulmonary nodules or masses. Experience with 1027 consecutive cases. Chest 1995;108:131-7.

18 Zakowski MF, Gatscha RM, Zaman MB. Negative predic tive value of pulmonary fine needle aspiration cytology. Acta Cytol 1992;36:283-6.

19 Crosby JH, Hager B, Hoeg K. Transthoracic fine-needle aspiration. Experience in a cancer center. Cancer 1985;56: 504-7.

20 Alonso P, Sanchez S, Ramirez E, Cicero R. Transthoracic needle biopsy in neoplastic and non-neoplastic pathology: experience in a general hospital. Diagn Cytopathol 1986;2: 284-9.

21 De Gregoria Ariza MA, Alfonso Aguiran ER, Villavieja Atance JL, et al. Transthoracic aspiration biopsy of pulmonary and mediastinal lesions. Eur $¥$ Radiol 1991;12:98-103.

22 Lovett JV, Manalo PB, Barcia TC, Bomberger RA, McGregor DB. Diagnosis of pulmonary masses by fine-needle aspiration. Am f Surg 1988;156:441-5.

23 Hayes MMM, Zhang DY, Brown W. Transthoracic fineneedle aspiration biopsy cytology of pulmonary neoplasms. Diagn Cytopathol 1994;10:315-19.

24 Cristallini EG, Ascani S, Farabi R, Paganelli C, Peciarolo A, Bolis GB. Fine-needle aspiration biopsy in the diagnosis of intrathoracic masses. Acta Cytol 1992;36:416-22.

25 Kazerooni EA, Lim FT, Mikhail A, Martinez FJ. Risk of pneumothorax in CT-guided transthoracic needle aspiration biopsy of the lung. Radiology 1996;198:371-5.

26 Stanley JH, Fish GD, Andriole JG, Gobien RP, Betsill WL Laden SA, et al. Lung lesions: cytologic diagnosis by fine-needle biopsy. Radiology 1987;162:389-91

27 Winning AJ, McIvor J, Seed WA, Husain OAN, Metaxas N. Interpretation of negative results in fine needle aspiration of discrete pulmonary lesions. Thorax $1986 ; 41: 875-9$.

28 Caya JG, Clowry LJ, Wollenberg NJ, Tieu TM. Transthoracic fine-needle aspiration cytology. Analysis of 82 patients with detailed verification criteria and evaluation of false negative cases. Am 7 Clin Pathol 1984;82:100-3.

29 Kato H, Konaka C, Kawate N, Yoneyama K, Nishimiya K, Saito $\mathrm{M}$, et al. Percutaneous fine-needle cytology for lung cancer diagnosis. Diagn Cytopathol 1986;2:277-83.

30 Tao LC, Weisbrod GL, Pearson FG, Sanders DE, Donat EE, Filipetto L. Cytologic diagnosis of bronchioloalveola carcinoma by fine-needle aspiration biopsy. Cancer 1986 ; 57:1565-70.

31 Lozowski W, Hajdu SI. Cytology and immunocytochemistry of bronchiolo-alveolar carcinoma. Acta Cytol 1987;31: 717-25.

32 Penketh ARL, Robinson AA, Barker V, Flower CDR. Use of percutaneous needle biopsy in the investigation of solitary pulmonary nodules. Thorax 1987;42:967-71.

33 Fraser RS. Transthoracic needle aspiration. The benign diagnosis. Arch Pathol Lab Med 1991;115:751-61.

34 Khouri NF, Stitik FP, Erozan YS, Gupta PK, Kim WS, Scott WW Jr, et al. Transthoracic needle aspiration biopsy of benign and malignant lung lesions. $A \mathcal{F} A \mathrm{Am} \mathcal{F}$ Roentgenol 1985;144:281-8. 